\title{
"Community First" for Whom? Reflections on the Possibilities and Challenges of Community-Campus Engagement from the Community Food Sovereignty Hub
}

\author{
Lauren Kepkiewicz, Charles Z. Levkoe, Abra Brynne
}

\begin{abstract}
While community-campus engagement (CCE) has gained prominence in postsecondary institutions, critics have called for a more direct focus on community goals and objectives. In this paper, we explore the possibilities and limitations of communitycentred research through our collective experiences with the Community First: Impacts of Community Engagement (CFICE) and the Community Food Sovereignty (CFS) Hub. Drawing on a four-year research project with twelve community-campus partnership projects across Canada, we outline three key areas for reflection. First, we examine the meanings of community-centred research-called "community first"-in our work. Second, we explore key tensions that resulted from putting "community first" research into practice. Third, we discuss possibilities that emerged from attempts to engage in "community first" CCE. We suggest that while putting "community first" presents an opportunity to challenge hierarchical relationships between academia, western ways of knowing, and community, it does not do so inherently. Rather, the CCE process is complex and contested, and in practice it often fails to meaningfully dismantle hierarchies and structures that limit grassroots community leadership and impact. Overall, we argue for the need to both champion and problematize "community first" approaches to CCE and through these critical, and sometimes difficult conversations, we aim to promote more respectful and reciprocal CCE that works towards putting "community first."
\end{abstract}

KEYWORDS community-campus engagement; community first; food sovereignty; food systems; Canada; community-based research

Community-Campus Engagement (CCE) has gained popularity amongst academics across North America. CCE is a concept that includes a broad range of research and teaching activities such as community-based research, community service-learning, and other forms of engagement between community-based organizations and postsecondary institutions (Cronley, Madden, \& Davis, 2015; Israel, Schulz, Parker, \& Becker, 1998; Schwartz, 2010). While CCE practices are diverse, here we use the term to describe partnerships between community-based organizations and university faculty, students, and staff that aim to create mutually beneficial relationships (Andrée et al., 2014; Levkoe et al., 2016; Strand, Cutforth, Stoecker, Marullo, \& Donohue, 2003).

Despite its many successes, critics have argued that CCE tends to privilege postsecondary 
institutions instead of community goals and objectives (Bortolin, 2011; Dempsey, 2010). Despite these sentiments, there is little documentation and study of what it means to put "community first" in CCE. Even among attempts to articulate and implement these efforts (for example, Cronley et al., 2015; Levkoe et al., 2016; Ward \& Wolf-Wendel, 2000), few studies have discussed what the concept of "community-centred" or "community first" means to community and academic participants as well as the resulting opportunities and challenges arising from participants' different goals and objectives within this framework.

In this article, we focus on "community first" CCE used by the Community First: Impacts of Community Engagement (CFICE), Community Food Sovereignty (CFS) ${ }^{1}$ Hub to frame our research. In doing so, we do not suggest that "community first" CCE is necessarily the ideal way to structure community-campus partnerships in all contexts; rather, we use it as a way to examine our own aspirations and to understand how our research practices measured up to our theoretical framings within CFICE. As members of the CFS Hub management team, we examine what "community first" has meant in theory and practice within our research. While we draw general conclusions that might be helpful to others working on community-centred research, we offer the following as reflections that are specific to our own research experiences with the CFS Hub.

CFICE is a Pan-Canadian action research project that works with academics and community groups to better understand how community-campus partnerships can be designed and implemented to maximize value for community-based organizations. Established in 2012, the first phase of the project was structured to work through interconnected hubs focusing on social, economic, and environmental issues, each with community and academic co-leads. The CFS Hub was established to advance food sovereignty, "the right of peoples to healthy and culturally appropriate food produced through ecologically sound and sustainable methods, and their right to define their own food and agriculture systems" (Nyéléni, 2007). Between 2012 and 2016, the CFS Hub worked closely with Food Secure Canada (FSC), the Canadian Association of Food Studies (CAFS), and about 30 community and academic partners to explore different models of CCE and, in doing so, to share approaches and practices that support food sovereignty in Canada. ${ }^{2}$

As part of the CFS Hub management team, the three authors of this paper ${ }^{3}$ shared the

\footnotetext{
${ }^{1}$ When established, the CFS Hub was originally named the Community Food Security Hub. In the second year of the project, the name was changed to the Community Food Sovereignty Hub to reflect the participants' values and the direction of the research.

2 The CFS Hub supported twelve demonstration projects across Canada including: The Regina Food Assessment, A Developmental Evaluation to Explore a Budding Community/Academic Collaboration, Creating a Food Hub through University-Community Partnership, Edible Campus: From Showcase to Living Classroom, Planning for Change: Community Development in Practice, Local Food Multipliers and Accessibility in Northern Ontario, Models of Community University Collaboration in the Waterloo Region Food System, Cross-Cultural Food Networks: Building and Maintaining Inclusive Food Security Networks to Support Indigenous and Non-Indigenous Communities, Campus Food Initiative Study, Paying for Nutrition: Income and Food Costs Across Canada, Sharing the Table Manitoba: SustainableLocal Food Systems, Regulation and Policy-Making in Manitoba, Responsibility and Relationships: Decolonizing the British Columbia Food Systems Network/Indigenizing our Praxis.

${ }^{3}$ Cathleen Kneen was the fourth management team member.
} 
goal of creating sustainable, equitable food systems through grassroots food sovereignty movements. Through the CFS Hub and its focus on "community first" research, we saw an opportunity to address community needs and advance food sovereignty in Canada. However, we each came from different perspectives and played different roles within the CFS Hub. Abra Brynne worked as a staff member with FSC as well as a demonstration project partner with the British Columbia Food Systems Network. Charles Levkoe began as the academic lead on the Planning for Change demonstration projects before assuming the role of the CFS Hub's academic co-lead. Lauren Kepkiewicz was employed as the CFS Hub's research assistant while completing a $\mathrm{PhD}$. All three authors had worked within the Canadian food movement and had experience doing food systems research. Taking these different positionalities into consideration, we use this paper as an opportunity to collaboratively reflect on key challenges and possibilities in doing "community first" research within the CFS Hub.

In the following section, we begin by describing CCE in relation to a history of inequity that has valued academic ways of knowing above community-based epistemologies and privileged dominant western approaches to knowledge. ${ }^{4}$ This section provides context for understanding some of the structural constraints on our attempts to do "community first" research within the CFS Hub. Next, drawing on our collective experiences within the CFS Hub, we reflect on three key areas. First, we explore the meaning of "community first" CCE within the CFS Hub and how our understandings of this approach developed. Second, we address key tensions in putting "community first" research into practice within the CFS Hub, including timelines and funding structures that re-centred academic control over the research process. Third, we outline possibilities that emerged from our attempts to put "community first" in CCE.

We conclude that "community first" has been an important aspiration; however, the process for doing this type of CCE work has been complex and contested. Despite our best efforts, we fell short of our aim to engage in research that benefitted communities first and foremost. While emphasizing the importance of working towards "community first" CCE, we are cautious of our ability to do so meaningfully in the present political and economic context where academic institutions privilege western and academic knowledge and expertise. We emphasize the structural limitations of "community first" CCE, acknowledging that "community first" CCE is extremely difficult, if not impossible, to achieve within current academic structures. Furthermore, community first approaches do not inherently challenge western epistemologies, as this depends not only on a project's orientation but also on the particular individuals and communities involved. Additionally, we suggest that "community first" research can reproduce dominant western ways of knowing, depending on the communities one works with. In this context we encourage CCE practitioners to problematize

\footnotetext{
${ }^{4}$ Western knowledge refers to a system that privileges particular forms of knowledge and practice. It is premised on an epistimelogy that privileges the scientific method, positivism, individuality, objectivity, and the separation and quantification of time, space, and relationships with the natural world (Tuhiwai Smith 2008). Following Said, Foucault, and Hall, Tuhiwai Smith explains that western knowledge is based in systems of classification and representation "which are coded in such ways as to 'recognize' each other and either mesh together, or create a cultural 'force field' which can screen out competing and oppositional discourses" (p. 47). This is done in order to define certain people as humans and others as not-humans, with the purpose of ensuring ongoing Western dominance.
} 
framings of "community first" that assume a homogeneous definition of community. Rather, it is necessary to be clear about which communities - and whose communities - research prioritizes, recognizing that the principles and mechanisms for engagement may be distinct (e.g. for small businesses, municipal governments, non-profit organizations, and/or social movements).

Because academics and community members face a complex array of challenges in conducting "community first" research, the label should be used with caution. However, this should not dampen the aspiration to achieve more community-focused collaborations. Overall, we argue for the need to both champion and problematize "community first" CCE methodologies in ways that challenge academic institutions that uphold western and academic ways of knowing. Through these critical, and sometimes difficult conversations, our aim is to engage in more respectful, reciprocal, and equitable research relationships that benefit "communities first".

\section{"Community First" Community-Campus Engagement?}

CCE can be broadly described as partnerships between campus-based actors (including postsecondary students, postdoctoral fellows, instructors, faculty, and their institutions) and community-based practitioners and activists (including private, public, and non-profit sectors). CCE partnerships include research and teaching intended to support communitybased organizations to meet their goals while making campuses more relevant and accountable to their communities. While CCE includes a range of approaches (e.g. community-based research, participatory action research, or service-learning), each shares a commitment to building respectful and mutually beneficial partnerships. Central to these relationships is the assumption that partnerships are based on the reciprocal and meaningful exchange of knowledge and resources (Carnegie Elective Community Engagement Classification, 2015; Flicker, 2008).

Despite positive intentions (for the most part), critics have argued that unreflexive approaches to community-based research can reproduce hierarchical relationships that privilege campuses and fail to adequately address community needs and knowledge (Bortolin, 2011; Flicker, 2008). For many community-based practitioners, and particularly for non-profit organizations, priorities tend to focus on program delivery with limited capacity and resources to take on research-related projects. As the network Incite! Women of Colour Against Violence (2007) argues, this is due, in part, to funding obligations and the immediacy of social needs that would otherwise go unmet, particularly within the current context of neoliberalization. ${ }^{5}$ For example, the Incite network argues that neoliberal policies have placed increasing responsibility for delivering direct services on non-profit organizations rather than the state while at the same time demanding that non-profits increasingly structure themselves like businesses, often limiting their abilities to push for radical social-justice programing and advocacy. Further,

\footnotetext{
${ }^{5}$ Neoliberalism has been described as a series of political and economic practices giving primacy to entrepreneurial freedom, strong private property rights, individual liberty, free markets and free trade as a way to advance human wellbeing (Harvey, 2005). The term 'neoliberalization' denotes that this is a dynamic system and not fixed in time.
} 
critics have also noted that many community-campus partnerships perpetuate dominant social relations with no intention to challenge systems of inequality or to change underlying causes (Butcher, Bazzina, \& Moran, 2011; Butin 2010; McBride, Brav. Menon, \& Sherraden, 2006). For example, while community-based knowledge and experiences are an essential part of research, the academy often fails to recognize these as credible or legitimate (Tuhiwai Smith, 1999).

Although different forms of CCE have attempted to address these critiques, they remain embedded in broader contexts of exploitation and inequity. In many cases, community members, and particularly marginalized communities, have experienced the academy as an elitist institution with rules and regulations that work to legitimize certain types of knowledge and knowers, positioning western (e.g., predominantly white, male, settler, upper class) epistemologies above community-based experiences and knowledges, particularly those originating within Indigenous communities and other marginalized groups (Battiste, 2008; Kovach, 2009; Simpson, 2011; Tuck 2009; Tuhiwai Smith, 1999). For example, Tuhiwai Smith (1999) argues that academic institutional rules, regulations, and expectations have created a context in which, "Western ideas about the most fundamental things are the only ideas possible to hold, certainly the only rational ideas, and the only ideas which can make sense of the world, of reality, of social life, and of human beings" (p. 56). These assumptions centre western knowledge production that prioritizes presumed rationality and objectivity over heart-, experiential- and emotion-based ways of knowing (Hart, Straka, \& Rowe, 2017). They also assume academic ownership over all data, and position academia as the only space in which 'legitimate' knowledge production occurs (Tuhiwai Smith, 1999).

Although we believe that "community first" CCE in its ideal form must challenge both western and academic epistemologies, we also recognize that as white, non-Indigenous researchers we operate within and benefit from institutional structures predicated on extractive relationships and the legitimization of specific ways of knowing over others. Thus we have a particular responsibility as "community first" CCE practitioners to challenge and change "the histories, social relations and conditions that structure groups unequally" (Verjee, 2012, p. 66), and "create new structures of engagement" (Sheridan \& Jacobi, 2014, p. 13). Without these actions for change, we do not believe it is possible to engage in CCE that puts "community first" and decentres western knowledge production.

\section{Methodologies}

Our collective reflection for this article began with a roundtable session organized at the 2015 CAFS Assembly entitled, Power Dynamics in Community Campus Partnerships for Food Sovereignty. The session brought together academic and community partners involved in the CFS Hub to share perspectives of the power dynamics within attempts to put "community first" in the demonstration projects and the CFS Hub more broadly. The session was recorded, transcribed, and analyzed as a starting point for developing this paper. In presenting our reflections, we also draw from evaluations conducted by the CFS Hub and final reports from demonstration project partners. As part of our collective reflection, we kept notes of discussions and 
reflections throughout our work with the CFS Hub.

While we have worked collaboratively as the CFS Hub management team, it is important to highlight our different roles, positionalities, and perspectives. As a community co-lead and staff with FSC from 2012 to 2015, Abra is a community-based researcher and seasoned activist with extensive knowledge of food systems as well as experience working with social movements and CCE projects. When the opportunity arose to take on the role of academic co-lead of the CFS Hub, Charles was eager to work more closely with community and academic leaders within Canadian food movements. Mobilizing his experience in the non-profit and agricultural sectors, Charles was responsible for ensuring the broad visions and objectives of CFICE were implemented through the research partnerships. As the research assistant for the CFS Hub, Lauren provided research and logistical support to the demonstration projects as well as the CFS Hub management team, while being greatly influenced by grassroots activist work within Indigenous and settler food movements. In the following three sections, we present key reflections on what "community first" has meant within CFICE as well as how it has worked in practice within the CFS Hub.

\section{Reflection \#1: What does "community first" mean within CFICE and the CFS Hub?}

As discussed above, CFICE was established in response to critiques that many CCE projects fail to adequately engage in research and teaching that puts "community first." In this context, CFICE aimed to establish "healthier, more democratic and longer-lasting communitycampus relationships" (CFICE, n.d.). According to the website for the overarching project, "being community first means engaging in equitable partnerships to co-create knowledge and action plans for addressing pressing community issues" (CFICE, n.d., emphasis in original). ${ }^{6}$ These efforts are rooted in a belief that collaborative and mutually-beneficial communityacademic partnerships (including knowledge co-creation and mobilization) are essential to more sustainable futures. During the first phase of CFICE, (from 2012-2015), this belief manifested through the establishment of five independent-operating thematic hubs that were co-developed and led by academic and community partners. ${ }^{7}$

To examine the question of how to do "community first" CCE research, CFICE worked with academic and community partners to co-develop project goals, objectives, methods, and underlying concepts. These partners came together within each hub as well as through quarterly program committee meetings to reflect on the progress and to make decisions about the overall project direction. While there was some turnover of participants, community organizations were actively involved throughout the project.

Within the CFS Hub, our understanding of "community first" built on the larger project's definition of the phrase, while at the same time adapting it to address the specific goals and needs of our academic and community partners. In addition to core partners Food Secure

\footnotetext{
${ }^{6}$ Although the CFS Hub is one of the thematic hubs under CFICE, the authors were not involved in developing the initial "community-first" vision, definitions, and methodologies of the project.

${ }^{7}$ The five thematic hubs included: The Community Food Sovereignty Hub, the Poverty Reduction Hub, the Community Environmental Sustainability Hub, the Violence Against Women Hub, and the Knowledge Mobilization Hub.
} 
Canada and Canadian Association of Food Studies, the CFS Hub had over 30 community and academic participants engaged in the demonstration projects over the first four years of the project. For the CFS Hub, building a "community first" approach meant that CCE work must take direction from its core community partner, FSC, who is a key convener of Canadian food movements. As a result, one of the main goals of the CFS Hub was to provide core support for a network of community-campus partnerships that intersected with FSC's key program areas: zero hunger, healthy and safe food and sustainable food systems (Food Secure Canada [FSC], n.d.). ${ }^{8}$

The CFS Hub was originally composed of one community co-lead and one academic co-lead; as relationships and trust developed over time, the management team evolved to include the research assistant as well as an FSC staff liaison. Through this evolution the CFS Hub developed a horizontal governance structure based on developing consensus among all members (Kepkiewicz, Srivastava, Levkoe, Brynne, \& Kneen, 2017). The ongoing participation of a FSC staff liaison enabled continuity within the CFS Hub, ensuring that a representative from FSC would be part of decision-making processes. This involvement and collaborative decision making structure was a key aspect of the CFS Hub's attempt to engage in "community first" CCE.

Another attempt to engage in "community first" CCE included supporting Canadian food movement networks by providing small pots of funding to twelve CCE demonstration projects. Each of the projects was based on existing collaborations between community-based practitioners and academic researchers working to transform food systems in Canada. The CFS Hub funds sought to enable the extension and evaluation of these projects' relationships, with the intention to better understand how non-profit community organizations can effectively share control of and benefit from community-campus partnerships. Each demonstration project received funds to participate for one year, with additional communication and evaluation over the duration of the project. Some participants contributed to CFS Hub presentations to share their work and experiences at FSC's biannual assemblies and annual CAFS conferences.

The relationship between demonstration project partners and the CFS Hub was guided by collaborative partnership agreements co-created and negotiated with each demonstration project to ensure that all those involved had an opportunity to contribute to the vision, objectives, and practical details of the partnership. While the demonstration project partners retained ultimate control in determining the direction of their CCE project partnerships, the collaborative agreement provided a platform to articulate how they would work with the CFS Hub to expand and evaluate these partnerships.

While the original intention was to have a representative from each demonstration project involved in the CFS Hub's decision making, this proved difficult. Many community practitioners had neither time nor resources to participate in work that was not directly connected to organizational projects. Recognizing these limitations, the CFS Hub management

\footnotetext{
${ }^{8}$ Of note, not one of the management team members (including this article's authors) was directly involved in the initial process due to personnel changes in the project over time. This situation is not uncommon in long-term projects due to staff changes, personal leaves, and unexpected illness.
} 
team attempted to maintain communication with each demonstration project, for example, by providing news and updates through the CFICE website and CFS Hub newsletters. Demonstration project partners and the CFS Hub also came together to co-author several reports and academic articles and share their experiences through a series of conference presentations, workshops, and webinars. These initiatives helped to articulate learnings and reflect on what it means to engage in research and teaching that attempt to put "community first."

By describing the ways that CFICE and the CFS Hub understood and attempted to put "community first" CCE into practice, our intention is to reflect on how we engaged in collaborative research and decision-making processes. These attempts included working closely with FSC staff and supporting a network of community organizations building food movements in Canada. However, we also recognize that we were not always effective in engaging in CCE that puts "community first." In the next section, we identify the limitations of our work, including our own mistakes as well as broader institutional constraints.

\section{Reflection \#2: What have been the key tensions in putting ideals of "community first" into practice?} Reflecting on the ways that "community first" was put into practice within the CFS Hub, we highlight several key challenges. In particular, we outline how our own project design and methodology decisions did not always support our "community first" vision but instead entrenched research practices that centre academic power over funding, timelines, and definitions of community. Further, we recognize that these practices are rooted in institutional structures that prioritize academic ways of knowing and, in doing so, perpetuate power inequities between different actors. Taking both these personal and structural factors into consideration, our intention is to critically reflect on the limitations of our attempts to disrupt conventional approaches to CCE and academic research more generally. We see this reflection process (and the actions that follow) as a key part of moving towards "community first" CCE.

In CFS Hub work, we found that timelines were often dictated by academic needs and research practices that took precedence over those of the community. For example, predetermined academic funding structures and University ethics applications required clear start and end dates, a linear timeline that begins with background research, proceeds to data collection and analysis, and concludes with disseminating research findings rather than a timeline designed to facilitate community partner projects and build relationships (as key method and outcome of knowledge production). While in some cases this was not a problem, in others, community partners expressed concern that the project was moving too quickly without adequate time to build trust and create and revisit mutual understandings and guidelines for relationships and research (although the development of collaborative agreements discussed above were helpful). As such, academic ways of conducting research and producing knowledge were often prioritized with timelines focused on the collection and dissemination of "data" rather than continually nurturing and renegotiating relationships.

Academic funding structures also set timeframes that often did not match communitybased timelines that centred on ongoing work and relationship-building. Although we had

Engaged Scholar Journal: Community-Engaged Research, Teaching, and Learning 
hoped to continue relationships beyond the one-year duration of the demonstration project partnerships, once the project funding was spent, many community partners felt unable to continue to engage without additional supports for staff time and resources. This was significant because a year was often just enough time to begin building relationships. For example, one community-based practitioner told the CFS Hub management team that they had just begun to develop trust for building meaningful research relationships when the first phase of the project was ending and the CFS Hub was set to dissolve. As a result, the individuals who had developed the partnership were no longer funded, nor were there further funds available to support the emerging relationship. While this did not prevent the partners from continuing relationships on an individual basis, we/they were not supported in doing so at the CFS Hub level or as part of the larger project, which continued onto a different research phase.

In Figure 1, Abra illustrates how community-based participants experienced academic engagement within the demonstration projects as well as between the demonstration projects and the CFS Hub. The sentiment is that academic engagement with community is typically broken into several phases based on availability in contrast to community timelines, which often stretch over long periods of time in order to accomplish their goals. Within our project, university structures often demanded that community-campus partnerships work in relation to the ebb and flow of students and faculty, rather than building long-term relationships, while community-based organizations' work is generally shaped by ongoing community needs and pressures.

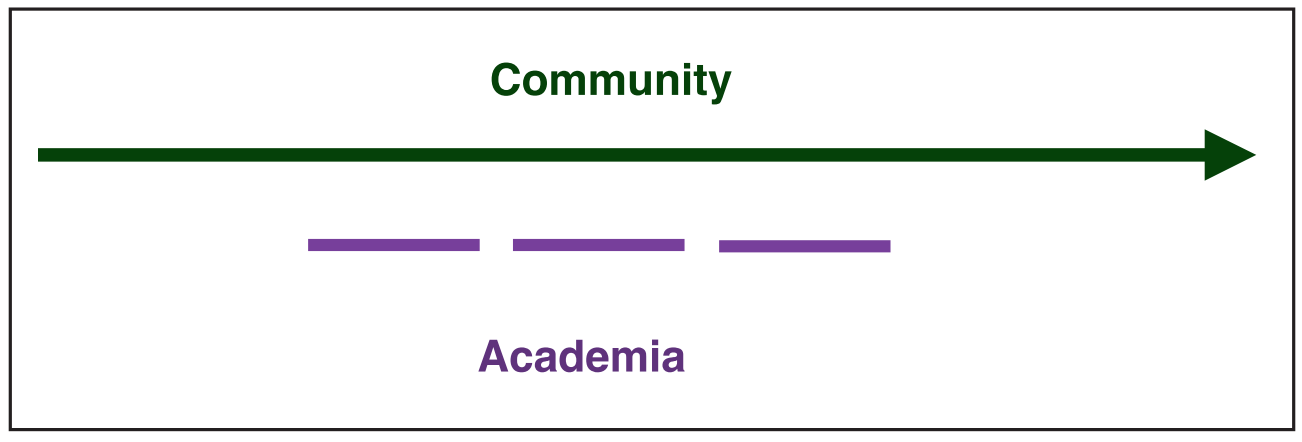

Figure 1. Brynne's visual depiction of academic engagement in community initiatives

A second major tension in our attempts to put "community first" occurred around funding. While academics in Canada do not typically raise money for their own salaries, they rely on funding to purchase equipment, hire researchers, support students, conduct research, and advance their careers. In contrast, most community organizations involved in the CFS Hub were dependent on raising funds for day-to-day activities, staff salaries, and general operations. Within the CFS Hub, each demonstration project received approximately $\$ 5,000$ to support and evaluate a pre-existing CCE project working towards food sovereignty. Some projects received additional funding for travel to conferences and meetings (e.g. FSC and 
CAFS Assemblies) as well as supports to share research findings, including webinars, public reports, and podcasts. The collaborative agreements outlined mutually agreed responsibilities and outputs, yet the demonstration projects had significant flexibility for how they used the funding. For example, one project used the money to hire a consultant to conduct a formal project evaluation followed by a workshop to discuss evaluation themes. Another project directed funds towards staff time to increase organizational capacity to reflect on the project and improve communications.

While demonstration projects had primary authority to spend the funds, and most used the money to suit their needs, multiple demonstration projects reflected that the funds were more work to administer than they were worth. For example, partners pointed to the significant time it took to receive the funding and to comply with bureaucratic requirements. Additionally, demonstration project partners underlined the need for Community-Campus Engagement partnerships to come with more substantial and sustained funding. While tenured academic researchers have a secure income that pays their salaries to engage in CCE, community-based practitioners operate in contexts where their positions can be extremely precarious, often tied to specific projects and with excessive work expectations for limited compensation.

Another major challenge faced was that the fundamental terms of the partnership were predetermined and controlled by the CFS Hub, the CFICE mandate, the administering university, and the funder. Although the activities of CFICE were designed to benefit CCE partnerships, for many community partners these benefits were either overly abstract, a mismatch with programs and obligations tied to funding sources, or too aspirational to be able to commit staff time and organizational resources.

Additionally, the CFS Hub was responsible for making decisions regarding which projects received funding as well as how to allocate other funds (e.g., for conference travel, research assistant salaries, and knowledge dissemination). Because funds originated from a federal research funding agency, monies needed to be administered by an academic institution. Further, the academic co-lead was ultimately responsible and accountable for all funding decisions. Although funding decisions were made collaboratively by the CFS Hub's management team, the primary authority over allocation of funds remained within the academy.

Another tension around funding arose when community partners did not fulfill the terms of the collaborative agreements. For example, some demonstration projects did not submit a final report, or declined to participate in ongoing CFS Hub activities. In this context, the management team felt more like a funder that had provided resources for evaluation, rather than a collaborative partner. Whereas the CFS Hub envisioned a collaborative relationship spanning the seven years of the larger project, there was only a small amount of direct funding for demonstration projects. In this context, we came to understand that many of the community-based organizations needed a funder rather than a research partner, especially smaller organizations that were over-worked and under-funded. In other words, organizations had limited capacity for building partnerships and instead often needed to focus on funding for their ongoing survival.

Reflecting on these tensions, we believe demonstration project partners may have viewed 
CFICE as a more valuable and genuine partner if the CFS Hub had the resources and mandate to more actively participate in and contribute to their project beyond the evaluation. This needed to be project-specific, which would have required additional resources and different kinds of experiences, beyond the capacity of the CFS Hub management team. In some cases, individuals from the CFS Hub management team used their personal expertise to support a demonstration project, but at the CFS Hub level, we were not particularly purposeful nor explicit about the value of these relationships. This contribution depended on a good match between the individuals involved. For example, Abra's experience with community-based activism and policy work related to meat production enabled her to contribute, in concrete ways, to a demonstration project focused on similar issues.

A third tension we encountered while attempting to put "community first" into practice was the way CCE tends to favour particular community members who are often part of formal organizations, rather than informal groups and social movements. Academic research structures are often more conducive to developing partnerships with community organizations that have well-established institutionalized structures. At the same time, formal organizations tend to be better positioned to work with academics. For example, despite an intention to support food sovereignty movements, the CFS Hub partnered primarily with registered nonprofit organizations. These kinds of community organizations are often perceived by academic institutions and funders to be more accountable and responsible due to their legal requirements as non-profits. They also tend to have more capacity, including the time needed for negotiating and building community-campus relationships, the ability to handle the administrative work accompanying these partnerships, and the ability to work with the research itself, with staff members who can be seconded or assigned to different projects.

However, while non-profit organizations play an important role in social and ecological justice efforts, they should not be construed as the movement. Most of the non-profit organizations we worked with had a specific mandate and a small number of professional staff and/or volunteers. These organizations and staff/volunteers certainly contributed to larger movements, but they were not necessarily representative of the broader grassroots communities who are integral to movements and movement-building.

While there are advantages to doing "community first" research with practitioners who are not involved in formal organizations, working with informal groups brings a different set of challenges. A lack of financial resources is often compounded among informal community actors, as funding bodies are often uncomfortable and/or unwilling to support individual activists and grassroots groups. While these groups typically have accountability mechanisms in place-based, for example, on interpersonal relationships and community networksacademic funding structures rarely value these as highly as formal mechanisms.

Understanding the different ways that our project's "community first" CCE research attempted to engage community actors is necessary within a context ripe with assumptions about who community includes and whose communities are prioritized. This understanding emerged during the first year of the CFS Hub, when the management team observed that organizations claiming to speak for community members may privilege particular perspectives 
and "represent a level of bureaucracy that can get in the way of understanding what community members really think, feel and need" (Andrée et al., 2014, p. 43). It is important to articulate the specifics of the community actors involved in "community first" CCE as well as engaging with the ways that communities include hierarchies and power imbalances. For example, a community-based activist expressed disappointment at the fact that CFICE had chosen to work with well-established community organizations in the area in which she lived. Furthermore, she expressed disappointment that such large academic projects were not doing more to support grassroots activists working to address structural issues and inequities within the community.

Our project's engagement with non-profit organizations meant that certain community members were more likely than others to participate in our research. Academic funding and administrative structures made non-profit organizations more attractive CCE partners, often resulting in partnerships with non-profit leaders who tended to be (but were certainly not always) white, middle-class, non-Indigenous, and generally unrepresentative of the entire communities they served. In this way, academic structures had a major influence on which community members - many rooted in western ways of knowing-were able to participate in our research. This, in turn, influenced the way the CFS Hub worked. For example, one partner suggested the linear depiction of time outlined in Figure 1 is rooted in a western perspective that fails to take into account understandings of time as circular.

While most of the demonstration projects aimed to transform food systems, we observed that non-profit organizations with formalized structures were generally less inclined than grassroots networks and activists to take on controversial projects in order to secure funding and appeal to the general public. In this context, it is important to understand which communities are more likely to be approached by academics as well as how the structures of research institutions better enable (as well as constrain) certain kinds of CCE.

\section{Reflection \#3: What are the Possibilities for Putting "Community First" in CCE?}

Despite the challenges in putting "community first" within CCE, our collective experiences suggest some key steps that academics and community-based practitioners can take to build more respectful and reciprocal relationships. While we believe "community first" research is an important goal, it is extremely difficult to achieve within academic institutions that continue to centre western methodologies, prioritize university "experts" over community knowledgeholders, and allocate funding to academics rather than community members. Still, we believe we must continue to work towards "community first" CCE by clearly articulating intentions and goals; recognizing and embracing differences as well as commonalities; ensuring research design and questions are determined by communities in collaboration with academic partners; and creating research that centres anti-colonial and social justice theories and practices.

First, we suggest that those involved in "community first" CCE clearly articulate intentions and goals from the outset, including being upfront regarding our capacity to meaningfully engage in "community first" research. Academics might ask: What limitations do I face in working toward a "community first" approach and are they surmountable within my current institutional context? For 
what and whose purpose am I asking to partner with community actors? Whose time am I taking and for whose benefit? Often, academics uncritically assume that their research is valuable, even if no tangible benefits exist for community partners. Likewise, community-based participants might ask: Is this partnership worthwhile to our organizational mandate? What are the key elements that we are not willing to compromise?

The Community Food Sovereignty Hub attempted to encourage these conversations through collaborative agreements between the demonstration projects and the management team. These agreements provided space to articulate goals and expectations, including expected outputs and potential benefits of the collaboration. Based on our experiences, taking time to develop the terms of CCE partnerships before beginning research (as well as revisiting these terms throughout the research) is a key part of ensuring that different partners' desires and goals are met. Additionally, we believe it is important to be upfront about whether and how our research is/was able to meet "community first" aspirations. In our case, it would have been helpful to use language that indicated we were working towards building "community first" CCE rather than assuming our CCE approach would inherently produce equitable research relationships.

Part of articulating and reflecting on research intentions and goals also leads to our second suggestion, which is for those involved in CCE research to understand and embrace differences and commonalities. For example, academics and community practitioners might ask: What do I have in common with the person/organization/university I am partnering with, and how are our goals and needs different? By asking these questions we underline the importance of partners critically reflecting on the ways in which we are positioned differently within our work. Our experiences have demonstrated that academics in particular (but community partners as well) need to approach "community first" CCE work with an understanding of the ways in which we are implicated in and benefit from institutional structures that privilege western and/or academic knowledge production. Even though academics working on "community first" CCE may not agree with this privileging, we/they often benefit from these structures, particularly white, settler, upper class, male academics. Similarly, partners may also be dominantly positioned within their communities and can benefit from additional critical reflection on their power and privilege. As a result, we believe that it is important to approach "community first" CCE relationships with humility, an ability to engage with positionalities, a commitment to building trust, and, finally, concrete actions to change institutional structures privileging certain bodies over others. Academics in particular need to avoid expectations of and entitlement to CCE partnerships.

Third, our experiences highlight the necessity of ensuring that communities, and particularly those most marginalized, have control over research design, purpose, and findings. Those involved in the research process might ask: How are decisions made relating to research questions, data, and dissemination of results? Who makes these decisions and who retains control over research data? Who is involved in the research process, and who is not? During the first year of the CFS Hub, a collaborative agreement with the British Columbia Food Systems Network, one of the demonstration projects, stated: "The individuals interviewed 
for this project, as well as members of the BC Food Systems Network, retain a high level of control over the research process, interpretation of results, and the sharing of results" (Chapman \& Martin, 2013, p. 2). Additionally, demonstration project evaluations suggested community research dissemination should include corresponding community-focused outputs, in conjunction with the publication of academic articles. Community outputs might include policy briefs or public forums, where findings are accessible, in both language and format, to a wide audience.

Fourth, we suggest the importance of adopting anti-colonial and social-justice research frameworks, especially when working with social movement organizations. While the content of anti-colonial and social-justice frameworks may be different depending on the context and partners, these frameworks provide necessary insight and actions to dismantle power hierarchies between academics and communities as well as within communities themselves. We suggest that those involved in the research might ask: How does this research challenge extractive research practices? How does it support marginalized community members while challenging power structures based on racial, gendered, colonial, and other hierarchies? How does this research partnership support movements for social justice and decolonization?

In general, we have found that, when academic and community partners approach partnerships with the aim of challenging social inequities through system-level change, these relationships establish a context in which all those involved can meaningfully begin to move towards "community first" CCE.

While these recommendations support more equitable and respectful "community first" CCE, we remain uncertain whether it is possible to create research that meaningfully puts "community first" within the confines of current structures that privilege academics and western ways of knowing. As we have outlined above, research funding is often structured to place significant power and decision-making in the hands of academics in CCE partnerships. Similarly, linear timelines tended to prioritize data collection and academic outputs rather than centring community epistemologies, which are often iterative, embedded in cultural and social practices, and relationship-based. Additionally, non-profit organizations are often chosen as CCE partners because funders and academics tend to see them as more accountable and better equipped to deal with the administrative work of CCE partnerships. However, these groups are often constrained by funding and organizational mandates in their ability to radically challenge social inequities in comparison to grassroots networks and activists. Additionally, our engagement with non-profit organizations and the particular bodies that tend to make up these organizations encouraged continued work within western knowledge production paradigms.

While we personally remain committed to "community first" CCE, we highlight the importance of embracing the complexities and specificities of doing so, recognizing that current funding structures as well as academic timelines and assumptions greatly inhibit "community first" approaches, demanding that our work challenge academic institutions and structures in order to better serve both the academic and non-academic communities with which we work. 


\section{Concluding Thoughts}

Reflecting on our collective experiences doing "community first" CCE, we highlighted CFICE's understanding of "community first" as the creation of equitable partnerships and the co-creation of knowledge. Building on this definition, the CFS Hub attempted to engage in "community first" CCE research by taking cues from FSC (our core community partner), and in doing so supported CCE partnerships aimed at building healthy, sustainable, and equitable food systems. However, while we believed these efforts were oriented towards "community first" CCE, we also underlined the ways that we fell short of meeting our goals. Our limitations were rooted both in our own mistakes as well as restrictions within academic systems, especially timelines and funding structures that facilitated academic control over CCE partnerships.

We also discussed the ways in which homogenous understandings of community led to CCE work that does not necessarily address power inequities either within or beyond communities. In particular, we highlighted the ways academic structures tend to privilege partnering with particular kinds of communities. For example, many non-profit organizations can be dominated by staff who benefit from dominant structures, and whose background is often (though certainly not always) rooted in western epistemologies.

While underlining the limitations of our research decisions, as well as broader institutional structures privileging western ways of knowing, we reflected on the possibilities of moving towards CCE that puts "community first" rather than simply assuming we were successful in doing this kind of work. We suggest that these possibilities might include:

- ensuring those involved in "community first" CCE partnerships can articulate intentions and goals;

- critically reflecting on and engaging with commonalities and differences amongst and between partners;

- ensuring communities have control over the research design and process; and

- employing anti-colonial and social justice frameworks demanding structural change and challenging inequities between and within universities and communities.

Although the reflections and suggestions presented above are not completely novel (see, for example, Bortolin, 2011; Cronley et al., 2015; McBride et al., 2006; Stoecker, Tryon, \& Hilgendorf, 2009; Ward \&Wolf-Wendel, 2000), by reflecting on our attempts to do "community first" CCE, we underline the need to unpack the complexities of doing this kind of research. Even when we know about and design research in attempts to avoid the reproduction of inequitable power relations and western ways of knowing, why do we continue to face the same kinds of challenges? In unpacking our own attempts to put "community first" in CCE, we call attention to the potential to reproduce dominant hierarchies and ways of knowing, even while aware and attempting to be subversive.

As such, this paper is part of our own process of recognizing mistakes as well as identifying the structural limitations we faced along with broader practices and assumptions that need to change. In doing so, we conclude that engaging in "community first" CCE, is an ongoing aspiration rather than a set of fixed methodologies that will inherently develop non- 
hierarchical relationships that challenge community-academic dichotomies. For us, this means that although the research frameworks and methods were incredibly important, we must work beyond these projects to challenge and change broader behaviours and structures that promote academic forms of knowledge over community-based knowledges, academic control of research over community-based research, and western ways of knowing over diverse forms of knowledge. In this way we echo the need for "community first" CCE practitioners to ensure that "educational institutions recognize the ideologies and practices of domination that structure how we relate to one another daily in maintaining subordination of others, and commit to institutional transformation" (Verjee, 2012, p. 66). We suggest that such institutional transformation must be considered part of "community first" practice even though it may go beyond specific "community first" CCE projects.

This process involves ongoing critical reflections on research and teaching by both community and academic participants, understanding the limitations within current research paradigms, and placing community goals and needs first while working together within anticolonial and social justice frameworks. In other words, academic needs, at times, may be forced to take a back seat to communities' needs. This rather literal translation of putting "community first" is a potential avenue for challenging academic research priorities and values. At the same time, we recognize that communities themselves involve tensions and hierarchies and may also privilege western epistemologies and ways of knowing. In this complex environment, we recognize that our work with the CFS Hub did not always achieve our aim to put communities first. We believe it is essential to engage with our limitations and be upfront about what we were and are able to achieve as this creates space for acknowledging the work still to be done to create a context in which meaningful "community first" CCE can happen. Despite these challenges, we maintain that it is important to work towards "community first" research by challenging academic and western ways of doing and knowing in research and teaching while critically reflecting on our own research choices and the communities with whom we work.

\section{About the Authors}

Abra Brynne has worked on food systems for the past 26 years, including policy and regulation, market access, and standards and conformity assessment. Abra was part of the CFICE management team and worked with Food Secure Canada and the BC Food Systems Network. Most recently, she has focused on decolonizing her food systems praxis.

Lauren Kepkiewicz (corresponding author) is a PhD candidate in the Department of Geography and Planning at the University of Toronto. Through her research, she attempts to understand the ways that food connects us to land in the context of the Canadian settler colonial state. Email: kepkiewicz@gmail.com 
Charles Z. Levkoe is the Canada Research Chair in Sustainable Food Systems at Lakehead University. His research focuses on social movement organizations and the growth of regional food networks in Canada. He has been active in investigations at the intersections of food movements and community-campus engagement.

Email: clevkoe@lakeheadu.ca

\section{References}

Andrée, P., Chapman, D., Hawkins, L., Kneen, C., Martin, W., Muehlberger, C., Nelson, C., Pigott, K., Qaderi-Attayi, W., Scott, S., \& Stroink, M. (2014). Building effective relationships for community-engaged scholarship in Canadian food studies. Canadian Food Studies, 1(1), 27-53.

Battiste, M. (2008). Research ethics for protecting Indigenous knowledge and heritage: Institutional and researcher responsibilities. In N.K. Denzin, Y. S. Lincoln, and L. T. Smith (Eds.), Handbook of critical and Indigenous methodologies (pp. 339-346). Thousand Oaks, CA: Sage.

Bortolin, K. (2011). Serving ourselves: How the discourse on community engagement privileges the university over the community. Michigan Journal of Community Service Learning,18(1), 49-59.

Butcher, J., Bezzina, M., \& Moran, W. (2011). Transformational partnerships: A new agenda for higher education. Innovative Higher Education, 36, 29-40.

Butin, D. (2010). Service-learning in theory and practice: the future of community engagement in higher education. New York: Palgrave Macmillan.

Campus Compact (2014). Carnegie elective community engagement classification. Retrieved from https:// www.niu.edu/outreach/documents/Definitions $\% 20$ of $\% 20$ Engagement/Carnegie $\% 20-\% 20$ Definitions $\% 20$ of $\% 20$ Engagement $\% 20$ and $\% 20$ Partneships.pdf

CFICE. (n.d.). What is CFICE? Retrieved from https://carleton.ca/communityfirst/

Chapman, D., \& Martin, W. (2013). Cross-cultural food networks: Building and maintaining inclusive food security networks to support Indigenous and non-Indigenous Communities. A report for Community First: Impacts of Community Engagement and the BC Food Systems Network. Retrieved from https://carleton.ca/communityfirst/wp-content/uploads/Cross-Cultural-FoodNetworks_FINAL-REPORT.pdf

Cronley, C., Madden, E., \& Davis, J.B. (2015). Making service-learning partnerships work: Listening and responding to community partners. Journal of Community Practice, 23(2), 274-289.

Dempsey, S.E. (2010). Critiquing community engagement. Management Communication Quarterly, 24(3), 359-390.

Flicker, S. (2008). Who benefits from community-based participatory research? A case study of the Positive Youth Project. Health Education \& Behavior, 35(1), 70-86.

Food Secure Canada (n.d.) CFICE Community Food Security Hub. Retrieved from: https:/ / foodsecurecanada.org/cfice-community-food-security-hub

Harvey, D. 2005. A brief history of neoliberalism. New York: Oxford University Press.

Hart, M. A., Straka, S., \& Rowe, G. (2017). Working across contexts: Practical considerations of doing Indigenist/anti-colonial research. Qualitative Inquiry, 23(5), 332-342. 
Incite! Women of Colour Against Violence. (2009). The revolution will not be funded. Durham and London: Duke University Press.

Israel, B., Schulz, A., Parker, E.A., and Becker, A.E. (1998). Review of community based research: assessing partnership approaches to improve public health. Annual Review of Public Health 19, 173-202.

Kepkiewicz, L., Srivastava, R., Levkoe, C., Brynne, A., \& Kneen, C. (2017). Community-campus engagement and the food sovereignty movement in Canada. In C. Buchanan, C. Anderson, J. Sanchez Rodriquez, M. Chang, \& T. Wakeford. (Eds.), Action research for food systems transformation. Reclaiming Citizenship and Diversity Series. Coventry: Coventry University.

Kovach, M. (2009). Indigenous methodologies: Characteristics, conversations, and contexts. Toronto, ON: University of Toronto Press.

Levkoe, C. Z., Andrée, P., Bhatt, V., Brynne, A., Davison, K. M., Kneen, C., \& Nelson, E. (2016). Collaboration for transformation: Community-campus engagement for just and sustainable food systems. Journal of Higher Education Outreach and Engagement, 20(3), 32-61.

McBride, A. M., Brav, J., Menon, N., \& Sherraden, M. (2006). Limitations of civic service: Critical perspectives. Community Development Journal, 41(3), 307-320.

Nyéléni. (2007). Forum for food sovereignty synthesis report. Retrieved from https://nyeleni.org/spip. php?page $=$ NWarticle.en\&id_article $=334$

Schwartz, K. (2010). Community engaged research: Student and community perspectives. Partnerships: A Journal of Service Learning and Civic Engagement, 1(2), 1-16.

Sheridan, M.P., \& Jacobi, T. (2014). Critical feminist practice and campus-community partnerships: A review essay. Feminist Teacher, 24(1-2), 138-150.

Simpson, L. (2011). Dancing on our turtle's back: Stories of Nishnaabeg re-creation, resurgence and a new emergence. Winnipeg: Arbiter Ring Publishing.

Stoecker, R., Tryon, E. A., \& Hilgendorf, A. (Eds.). (2009). The unheard voices: Community organizations and service learning. Philadelphia: Temple University Press.

Strand, K. J., Cutforth, N., Stoecker, R., Marullo, S., \& Donohue, P. (2003). Community-based research and higher education: Principles and practices. Hoboken, NJ: John Wiley \& Sons.

Tuck, E. (2009). Suspending damage: A letter to communities. Harvard Educational Review, 79(3), 409-427.

Tuhiwai Smith, L. (2008) [1999]. Decolonizing methodologies. New York: Zed Books.

Verjee, B. (2012). Critical race feminism: A transformative vision for service-learning engagement. Journal of Community Engagement and Scholarship, 5(1): 57-69.

Ward, K., \& Wolf-Wendel, L. (2000). Community-centered service learning. The American Behavioral Scientist, 43, 767-780. 